\title{
アルミナ質油脂研磨材の研究
}

山口悟郎・田辺漠

(東京大学工学部)

\section{Research on Fatty Abrasive of Alumina}

By Goro YAMAGUCHI and Hiroshi TANABE

(Faculty of Engineering, University of Tokyo)

缩言

油脂研磨材の5ち，精仕上用としては青棒とマチレ ス，粗仕上なたは下地用としてはトリポリとグロース がその大部分を占めていて，アルミナ質のるのは余り 普及されていない。この理田はアルミナ質のるのが性 能,価格ともと中途はんぱであるためで，この点が解決 されればもっと実用化されるすのと考克る。つ方精

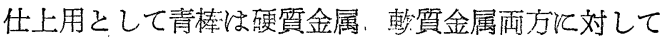
優秀な性能をるっているが高価である。マチレスは軟 質金属に対してのみ性能が優唀であるが低廉である。 アルミナ質のるのは精仕上用とする場合，バイヤー法 アルミナを原料とすれれ゙研磨力は両者の中間飞位する が，仕上力をそれらに匹敵させるためには相当研究の 余地がある。また，洒格は両者の中間である。アルミ ナ質のものを粗仕上用または下地用とすれば，性能は 極めて優秀であるが，従来のトリポリ，グロースに比 ベて価格炕きな差があるので，バイヤ一法アルミナ を使用することは不可能で，他の安価なアルミナ源を 使用しなければ実用化を期することができない。との

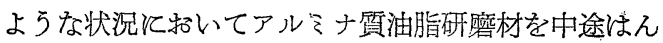
ぱな存在から能率よいるのとするための資料を得る目 的でこの実験在行った。

\section{I. アルミナの焼成度と研磨力}

アルミナは, $\gamma$ アアルミナの形ではスピネル類似の構
造で充塤度小さく，硬度が小さい上結晶発達も不十 分であるため研磨力る小さい。したがって の形で油脂研磨材江応用される。乙かし， $\alpha$-アルミナ そ和いてもその結晶の発達程度が研瞕力を大きく左右 し，製造方法により研磨力の異なったものが得られ る。これらの概略の性質を把握するため, 種々のアル ミナ源を買なった条件で焼成して製造したアルミナの 結晶度, 研磨力を試験した。酸,アルカリに対する溶 解度は, 粉末試料 $0.5 \mathrm{~g}$ を $90 \sim 95^{\mathrm{C}} \mathrm{C}$ で $2 \mathrm{~N}$ の硫酸

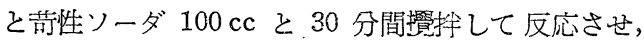
溶解した量の百分率で示した。研磨力は微枌末をオレ イン酸をもってペイスト状とし, 約 $0.4 \mathrm{~g}$ の粉末で約 $8 \mathrm{~cm}^{2}$ の NF 粗度が 50 〜0 の真錔 (Brs.), ニッケル $(\mathrm{Ni})$ ，ステンレス鋼（St）の面を手研磨した場合， 粗度が NF 13 以下となったものを上，10〜15 のも のを中，20 以上のものを下とした。吸湿量は気温， $10 \sim 15^{\circ} \mathrm{C}$, 湿度約 $60 \%$ の室内に 1 週間放置した時の 吸湿量百分率である。これらの結果を第 1 表に示す。 この結果で明かなように

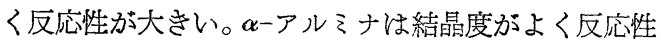
が小さいとともに研䜆力大きく，焼成温度を高くする こぞにより，この傾向を增大させることができる。ダ イアスポアは脱水によりただちと $\boldsymbol{\alpha}$ アアルラナとなる ため比較的低温でての傾向を与えることができる。

Table 1 Reactivity and abrasive power of calcined alumina

\begin{tabular}{|c|c|c|c|c|c|c|c|c|}
\hline \multirow{2}{*}{ Raw material } & \multirow{2}{*}{$\begin{array}{l}\text { Calcining } \\
\text { condition } \\
\left({ }^{\circ} \mathrm{C}\right) 1 \mathrm{~h}\end{array}$} & \multirow{2}{*}{$\begin{array}{l}+ \text { Result of } \\
\mathrm{X} \text {-ray } \\
\text { analysis }\end{array}$} & \multirow{2}{*}{$\begin{array}{l}\text { Solubility } \\
\text { by } 1 \mathrm{~N} . \\
\mathrm{H}_{2} \mathrm{SO}_{4}(\%)\end{array}$} & \multirow{2}{*}{$\begin{array}{l}\text { Solubility } \\
\text { by } 1 \mathrm{~N} \text {. } \\
\mathrm{NaOH}(\%)\end{array}$} & \multirow{2}{*}{$\begin{array}{l}\text { Humidity } \\
\text { absorption } \\
(\%) * *\end{array}$} & \multicolumn{3}{|c|}{ Abrasive Power to. +4} \\
\hline & & & & & & Brs. & $\mathrm{Ni}$ & $\mathrm{S} t$ \\
\hline \multirow{5}{*}{ diaspore } & raw & diaspore & 0.34 & 1.57 & 0.00 & $\mathrm{H}$ & $M$ & M \\
\hline & 500 & $x$ & 1.54 & 4.55 & 1.87 & $\mathrm{H}$ & $\mathbf{M}$ & $\mathrm{H}$ \\
\hline & 620 & $\alpha$ & 0.43 & 2.41 & $1: 05$ & $\mathrm{H}$ & $\mathrm{H}$ & $\mathrm{H}$ \\
\hline & 810 & $\alpha$ & 0.35 & 0.51 & 0.29 & $\mathrm{H}$ & $\mathrm{H}$ & $\mathrm{H}$ \\
\hline & 1000 & $\alpha$ & 0.33 & 0.47 & 0.15 & $\mathbf{H}$ & $\mathrm{H}$ & $\mathrm{H}$ \\
\hline \multirow{5}{*}{$\begin{array}{l}\text { aluminium } \\
\text { hydroxide }\end{array}$} & 610 & $\gamma$ & 12.51 & 18.35 & 14.31 & $\mathrm{H}$ & $\mathrm{L}$ & $\mathrm{L}$ \\
\hline & 800 & $\gamma$ & 9.30 & 15.96 & 7.71 & $\mathrm{H}$ & $\mathrm{L}$ & $\mathrm{L}$ \\
\hline & 1000 & $\gamma+\alpha$ & 2.44 & 3.54 & -1.05 & $\mathrm{H}$ & $\mathrm{L}$ & $\mathrm{M}$ \\
\hline & $1200^{\circ}$ & $\alpha$ & 0.37 & 1.31 & 0.22 & $\mathrm{H}$ & $\mathrm{H}$ & $\mathrm{H}$ \\
\hline & 1400 & $\alpha$ & 0.18 & 0.34 & 0.00 & $\mathrm{H}$ & $\mathrm{H}$ & $\mathrm{H}$ \\
\hline
\end{tabular}




\begin{tabular}{|c|c|c|c|c|c|c|c|}
\hline \multirow{4}{*}{$\begin{array}{l}\text { aluminium } \\
\text { acetate }\end{array}$} & 800 & $\gamma^{\prime}$ & 74.39 & 74.66 & 8.04 & $\mathrm{H}$ & $\mathrm{M}$ \\
\hline & 1000 & $\gamma+a$ & 2.64 & 11.12 & 4.06 & $\mathrm{H}$ & M \\
\hline & 1200 & $\alpha$ & 0.33 & 1.68 & 0.25 & $\mathrm{H}$ & $\mathrm{H}$ \\
\hline & 1400 & $a:$ & 0.22 & 0.38 & 0.12 & $\mathrm{H}$ & $\mathrm{H}$ \\
\hline \multirow{3}{*}{$\begin{array}{l}\text { ammonium } \\
\text { alum }\end{array}$} & 1010 & $\gamma+\alpha$ & 23.55 & 19.40 & 7.20 & $\mathrm{H}$ & $\mathrm{L}$ \\
\hline & 1200 & $\alpha$ & 0.87 & 1.00 & 0.36 & $\mathrm{H}$ & $\mathrm{H}^{\tau}$ \\
\hline & 1400 & $\alpha$ & 0.24 & 0.41 & 0.18 & $\mathrm{H}$ & $\mathrm{H}$ \\
\hline \multirow{3}{*}{$\begin{array}{l}\text { potassium* } \\
\text { alum }\end{array}$} & 1000 & $\gamma+\alpha$ & 0.95 & 2.82 & 0.17 & $\mathrm{H}$ & $\mathrm{H}$ \\
\hline & 1200 & $\alpha$ & 0.19 & 0.78 & 0.00 & $\mathrm{H}$ & $\mathrm{H}$ \\
\hline & 1400 & $\alpha$ & 0.04 & 0.40 & 0.00 & $\mathrm{H}$ & $\mathrm{H}$ \\
\hline
\end{tabular}

$\because$ after calcining washed by water

$+\alpha \cdots \cdots \cdot \boldsymbol{\alpha}-\mathrm{Al}_{2} \mathrm{O}_{3} \quad \gamma \cdots \cdots \cdot \gamma-\mathrm{Al}_{2} \mathrm{O}_{3}$

** $10 \sim 15^{\circ} \mathrm{C}, 60 \%$ humidity, for 1 week

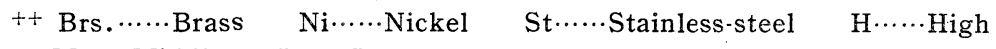

II. 油脂研磨材の性能試験法

試験用バフは直径 $15 \mathrm{~cm}$, 厚さ $2.5 \mathrm{~cm}$ の金属仕上 用バラバフで，試験条件は廻転計とより 2400 r.p.m. ワット計によりモーターへの入力を $1 / 8 \mathrm{PP}$ とでき5 る限り保つよ5努めた。バフに 0.3 0.4 g の油脂研 既材を附着させ，粗度 NF 40〜60 としたニッケル $(\mathrm{Ni})$, ステンレス鋁 $(\mathrm{St})$, 鈰 $(\mathrm{Cu})$, 真鍮 $(\mathrm{Brs})$, アル ミニウム $(\mathrm{Al})$ の面を研磨し，一定時間ごとと研磨方 向，物よびそれ飞直角の方向から NF 粗度を測定す る。この方法で市販の赤棒 (酸化鉄油脂研否材), 青棒 (酸化クロム油脂研喡材), マチレス（焼成ドロマイト 質油脂研磨材)，白棒（アルミナ質油脂研磨材）飞つ きステンレス鋼と対する性能試験した結果を第 2 表に 示す。

Table 2 Result of abrasive test

\begin{tabular}{|c|c|c|c|c|}
\hline $\begin{array}{l}\text { Name of } \\
\text { abrasive }\end{array}$ & 赤棒 & 青㮫 & マチレス & 白棒 \\
\hline & $\begin{array}{r}\text { Ferric } \\
\text { oxide }\end{array}$ & $\begin{array}{l}\text { Chromium } \\
\text { oxide }\end{array}$ & $\begin{array}{l}\text { Calcined } \\
\text { dolomite }\end{array}$ & 12 \\
\hline 2.5 & $* 15,16$ & 11,11 & 19,20 & 14,15 \\
\hline 5 & 13,14 & 11,11 & 15,17 & 13,14 \\
\hline 10 & 12,13 & 11,11 & 14,14 & 12,13 \\
\hline 20 & 12,12 & 11,11 & 12,12 & 11,12 \\
\hline 35 & 12,12 & 10,11 & 12,12 & 11,11 \\
\hline 60 & 12,12 & 10,11 & 12,12 & 10,11 \\
\hline
\end{tabular}

* left value is parallel direction; right value is crossing direction

この結果基いて研磨力 $P$ を次式とより表示する こととした。

$$
P=\frac{25}{t_{\mathrm{NF} 12}}
$$

ただし $t \mathrm{NF}_{12}$ に研磨により研磨方向つ粗度が $\mathrm{NF}$ 12 そなる時間を秒で表した值である。また研磨方向 の粗度が NF 12 となった時, 直角方向の粗度もこれ そ等しいもの，NF 13〜14 であるもの，NF 15 以上

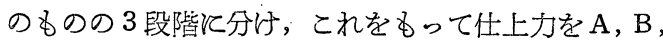
Cで表示することとした。第 3 表はこの表示方法をと った值である。以下試製アルえナ質油脂研磨材につい ては，すべてての方法とより試験し，性能をこの方式 とよって表示した。

Table 3. Abrasive power and finishing power

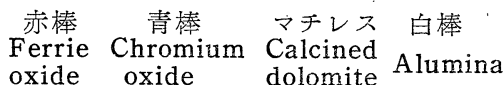

$\begin{array}{ccccc}\begin{array}{c}\text { Abrasive } \\ \text { power }\end{array} & 2.5 & >10 & 1.25 & 2.5 \\ \begin{array}{c}\text { Finishing } \\ \text { power }\end{array} & \text { B } & \text { A } & \text { A } & \text { B }\end{array}$

\section{III. バイヤー法アルミナによる油脂研磨材}

バイヤー法による水酸化アルミニウムを単味で，ま たは配合物を加兄て一定温度飞焼成し，ポットミルで 10時間粉砕後, 適量の硬化脂肪酸乙加温湜和して油脂 研磨材を製造した。この製品沉つき前述した試験法に より試験した。製造条件と試験結果を第 4 表に示す。 使用した脂肪酸は日本油脂製の水添とよる鯨油硬化脂 肪酸で, 純白色の融点 $56^{\circ} \mathrm{C}$ のものである。

Table 4 Properties of fatty abrasive from alumina of Bayer's process

\section{Addition} Calcining Condition
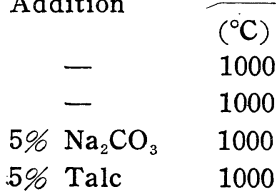
1000 1000 1000 1000 1100

(h)

0.5

3

3

3

0.5
Fatty acid
Abrasive and finishing power

\begin{tabular}{crrrr}
\hline $\mathrm{Ni}$ & $\mathrm{St}$ & $\mathrm{Cu}$ & $\mathrm{Brs}$ & $\mathrm{Al}$ \\
$0.7 \mathrm{~B}$ & $0.7 \mathrm{C}$ & $4.1 \mathrm{~B}$ & $2.5 \mathrm{~B}$ & $0.7 \mathrm{C}$ \\
$0.7 \mathrm{~B}$ & $0.7 \mathrm{C}$ & $6.2 \mathrm{C}$ & $3.6 \mathrm{~B}$ & $5 \mathrm{C}$ \\
$0.4 \mathrm{~B}$ & $2 \mathrm{C}$ & $5 \mathrm{C}$ & $2.5 \mathrm{C}$ & $2 \mathrm{C}$ \\
$0.7 \mathrm{~B}$ & $1.7 \mathrm{~B}$ & $8 \mathrm{C}$ & $5 \mathrm{~B}$ & $7 \mathrm{C}$ \\
$6 \mathrm{~B}$ & $5 \mathrm{~B}$ & $10 \mathrm{~B}$ & $10 \mathrm{~B}$ & $>10 \mathrm{C}$
\end{tabular}




\begin{tabular}{|c|c|c|c|}
\hline & - & 1100 & 3 \\
\hline $5 \%$ & $\mathrm{Na}_{2} \mathrm{CO}_{3}$ & 1100 & 3 \\
\hline $5 \%$ & Talc & 1100 & 3 \\
\hline & - & 1250 & 0.5 \\
\hline & - & 1250 & 1.5 \\
\hline $5 \%$ & $\mathrm{Na}_{2} \mathrm{CO}_{3}$ & 1250 & 1.5 \\
\hline $5 \%$ & Talc & 1250 & 1.5 \\
\hline & - & 1400 & 1 \\
\hline $5 \%$ & $\mathrm{Na}_{2} \mathrm{CO}_{3}$ & 1400 & 1 \\
\hline $5 \%$ & Talc & 1400 & 1 \\
\hline
\end{tabular}

ての結果で明かなようと，アルカリを添加するとと は $\boldsymbol{\alpha}$-アルミナの発達を阻害すると考光られ, 好まし くない。滑石の添加は研磨力をやや增加するが仕上力 を恵くするので，これる好ましくない。したがって精 仕上用としてはなるべく純粋なアルミナ源を使用する

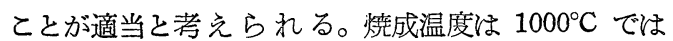
aーアルミナの発達が十分でなく， $1400^{\circ} \mathrm{C} て ゙ は$ 結晶が 発達しすぎて仕上力がやや低下する結果を示し，1100 〜 $1250^{\circ} \mathrm{C}$ が適当でめる。この範囲で銅，真鍮などの 軟質金属用にはやや低温がよい。アルミニウムと対し てはいずれる仕上力が不十分で，これとは配合油脂の 影響が極めて大きいと荐兄られ, 今後の問題とした い。

IV. ボーキサイトを原料とする油脂研磨材

バイヤー法アルミナのような純アルミナを原料とす るアルミナ質油脂研磂材は精仕上用としては引合5 が，粗仕上または下地研磞用としてはもっと安価なア

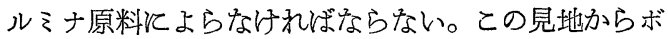
一キサイトをそのま原料とする方法を検討した。使

$\begin{array}{rrrrr}10 \mathrm{~B} & 10 \mathrm{~B} & >10 \mathrm{~A} & >10 \mathrm{~A} & >10 \mathrm{~A} \\ 1 \mathrm{~B} & 1.25 \mathrm{~B} & 5 \mathrm{~A} & 2.5 \mathrm{~B} & 5 \mathrm{C} \\ 4 \mathrm{~B} & 10 \mathrm{C} & >10 \mathrm{C} & >10 \mathrm{C} & >10 \mathrm{C} \\ 10 \mathrm{~B} & 10 \mathrm{~A} & >10 \mathrm{~B} & >10 \mathrm{~B} & >10 \mathrm{C} \\ 10 \mathrm{~B} & 10 \mathrm{~B} & >10 \mathrm{~A} & >10 \mathrm{~A} & >10 \mathrm{C} \\ 2.2 \mathrm{~A} & 3 \mathrm{~B} & 10 \mathrm{~B} & 5 \mathrm{~A} & 5 \mathrm{C} \\ 5 \mathrm{~B} & 10 \mathrm{~B} & 10 \mathrm{C} & >10 \mathrm{C} & 10 \mathrm{C} \\ 10 \mathrm{C} & >10 \mathrm{~B} & >10 \mathrm{C} & >10 \mathrm{~B} & >10 \mathrm{C} \\ 10 \mathrm{C} & 2.5 \mathrm{~B} & >10 \mathrm{~B} & 10 \mathrm{~B} & 5 \mathrm{C} \\ >10 \mathrm{~B} & >10 \mathrm{~B} & >10 \mathrm{C} & >10 \mathrm{C} & >10 \mathrm{C}\end{array}$

用したボーキサイトはビンタン産のもので成分を第 5 表に，熱天科試験，熱分析結果を第 1 図に示す。 550 ${ }^{\circ} \mathrm{C}$ 附近の吸熱脱水は粘土礦物怙よび二次生成したべ ーマイトの脱水と考光られる。

Table 5 Chemical composition of bauxite

$\begin{array}{cccccc}\text { Ig. loss } & \mathrm{SiO}_{2} & \mathrm{Al}_{2} \mathrm{O}_{3} & \mathrm{Fe}_{2} \mathrm{O}_{3} & \mathrm{CaO} & \mathrm{MgO} \\ 30.5 & (\%) & (\%) & (\%) & (\%) & (\%) \\ 3.6 & 52.9 & 10.1 & 1.3 & 0.3\end{array}$

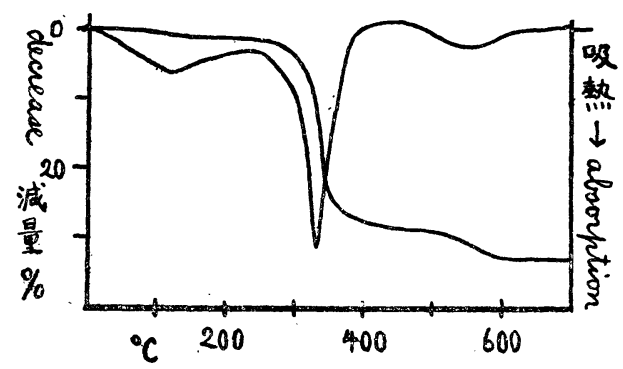

Fig.1 Thermal analysis and balance test of bauxite

このボーキサイトの加熱変化状態をX線分析とより 試験した結果を第 6 表に示す。

Table 6 Result of X-ray analysis of calcined bauxite

Calcined temp. Colour Result of X-ray analysis

$\left({ }^{\circ} \mathrm{C}\right)$ for $1 \mathrm{~h}$. Colour (Crystal form and crystaline grade)

$\begin{aligned} \text { raw } & \text { redish brown } \\ 600 & \text { redish brown } \\ 800 & \text { redish brown } \\ 1000 & \text { light brown } \\ 1200 & \text { light brown } \\ 1300 & \text { very light brown }\end{aligned}$

gibbsite only

almost amorphyus

$\gamma-\mathrm{Al}_{2} \mathrm{O}_{3}, \alpha-\mathrm{Fe}_{2} \mathrm{O}_{3}$ very low grade

$\alpha-\mathrm{Al}_{2} \mathrm{O}_{3}, \alpha-\mathrm{Fe}_{2} \mathrm{O}_{3}$ low grade

$\boldsymbol{\alpha}-\mathrm{Al}_{2} \mathrm{O}_{3}$ (somewhat solid solution of $\mathrm{Fe}_{2} \mathrm{O}_{3}$ ), $\boldsymbol{\alpha} \mathrm{Fe}_{2} \mathrm{O}_{3}$, medium grade $\alpha-\mathrm{Al}_{2} \mathrm{O}_{3}-\alpha \mathrm{Fe}_{2} \mathrm{O}_{3}$ (solid solution, $\mathrm{a}=5.19 \mathrm{kX}, \alpha=54^{\circ} 50^{\prime}$ ) high grade

とれらの結果からわかるように，ボーキサイト中の 水酸化アルミニウム（ジプサイト）は純水酸化アルミ ニウムと大体同様な熱変化をするが，やや異なる点は $\boldsymbol{\gamma \rightarrow \boldsymbol { a }}$ "の変化はいくらか低温で和こり始めること，乙 かし単結晶の発達程度は相当低いととなどである。ボ 一キサイト中の酸化鉄は原礦中にはほとんどアモーフ アスで存在するようであるが，加熱炕よって $\boldsymbol{\alpha}-\mathrm{Fe}_{2} \mathrm{O}_{3}$ となる。 $1200^{\circ} \mathrm{C}$ 加熱性いては $a:-\mathrm{Al}_{2} \mathrm{O}_{3}$ そわずか固 溶しているととが認められるが， $1300^{\circ} \mathrm{C}$ 加熱では明 かな固溶体を形成し $\mathrm{a}=5.19 \mathrm{kX}, \alpha=54^{\circ} 50^{\prime}$ と格子 が相当膨脹する。：
このよ5な焼成ボーキサイトをポットミルで10時間 粉研後, 適量の硬化脂肪酸乙加温混和して油脂研䂱材 を製造した。この製品の製造条件と試験結果を第 7 表 飞示す。

第 7 表の結果のよ5に，ボーキサイト焼成物は 1000 ${ }^{\circ} \mathrm{C}$ 焼成でも軟質金属に対しては相当の研磨力がある。

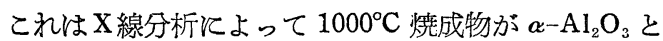
なっていることと一致する。さらに高温焼成のものは 焼結度が進んでいるので，X線分析の結果放られる よ5と舺結晶の結晶度は悪いが研禁力は大きい。しか し, 焼結性のため仕上力は純アルミナ製品に比べ数等 
Table 7 Properties of fatty abrasive from bauxite

\begin{tabular}{|c|c|c|c|c|c|c|c|}
\hline Calcining & Condition & Fatty acid & \multicolumn{5}{|c|}{ Abrasive and finishing power } \\
\hline$\left({ }^{\circ} \mathrm{C}\right)$ & (h) & $(\%)$ & $\mathrm{Ni}$ & St & $\mathrm{Cu}$ & Brs & Al \\
\hline 1000 & 3 & 25 & $2.5 \mathrm{C}$ & $2.5 \mathrm{~B}$ & $>10 \mathrm{C}$ & $>10 \mathrm{C}$ & $>10 \mathrm{C}$ \\
\hline 1100 & 3 & 25 & $10 \mathrm{~B}$ & $10 \mathrm{~B}$ & $>10 \mathrm{C}$ & $>10 \mathrm{C}$ & $>10 \mathrm{C}$ \\
\hline 1200 & 2 & 22 & $10 \mathrm{C}$ & $10 B$ & $>10 \mathrm{C}$ & $>10 \mathrm{C}$ & $>10 \mathrm{C}$ \\
\hline 1250 & 1.5 & 20 & $>10 \mathrm{C}$ & $10 \mathrm{~B}$ & $>10 \mathrm{C}$ & $>10 \mathrm{C}$ & $>10 \mathrm{c}$ \\
\hline 1350 & 1 & 20 & $>10 \mathrm{C}$ & $>10 \mathrm{C}$ & $>10 \mathrm{C}$ & $>10 \mathrm{C}$ & $10 \mathrm{C}$ \\
\hline
\end{tabular}

劣っている。したがって精仕上用としては最適とはい えないが，粗仕上または下地研㭲用として浪極めて優 秀な甠能をるっているといらととができる。

v. アルミ残灰を原料とする油脂研罯材 ボーキサイトの外安価なアルミナ源としては再生 アルミニウムの残渣であるアルミ残灰がある。アルミ

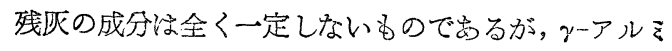
ナ, $\gamma$-スピネル1), $\alpha-$ ールミナ, 窒化アルミニウム, 金属アルミニウム，その他不純物などからなる。その 性状については一部既報した2゙。

本研究使用したアルミ残灰怯既謘の詿料の No.4 〜No.6 で五り, 第 8 表に標準酸化物こしての分析値 を示す。

Table 8 Analytical value of aluminous ash as normal oxide

\begin{tabular}{|c|c|c|c|c|c|c|c|c|c|c|}
\hline No. & $\underset{(\%)}{\text { Ig. loss }}$ & $\begin{array}{r}\mathrm{SiO}_{2} \\
(\%)\end{array}$ & $\begin{array}{l}\mathrm{Al}_{2} \mathrm{O}_{3} \\
(\%))^{2}\end{array}$ & $\begin{array}{l}\mathrm{Fe}_{2} \mathrm{O}_{3} \\
(\%)\end{array}$ & $\begin{array}{l}\mathrm{CaO} \\
(\%)\end{array}$ & $\begin{array}{r}\mathrm{MgO} \\
(\%)\end{array}$ & $\begin{array}{l}\mathrm{Cu} \\
(\%)\end{array}$ & $\begin{array}{c}\text { Total } \\
(\%)\end{array}$ & $\begin{array}{c}N \\
(\%)\end{array}$ & $\begin{array}{c}\mathrm{Cl} \\
(\%)\end{array}$ \\
\hline 4 & 0.18 & 9.07 & 82.08 & 3.80 & 0.80 & 6.19 & 0.53 & 102.65 & 0.56 & - \\
\hline 5 & 5.16 & 4.83 & 83.01 & 1.52 & 1.67 & 7.87 & 0.31 & 104.37 & 4.42 & 2.28 \\
\hline 6 & 4.12 & 10.43 & 97.71 & 3.42 & 1.50 & 3.39 & 0.15 & 120.76 & 1.23 & 1.4 \\
\hline
\end{tabular}

この值の N の量“招よび 合計の $100 \%$ 超過量から AlN および Al を換算して近似成分の推定值を求め

ると第 9 表のよ5となる。同時に X 線分析結果を示 す。

Table 9 Approximate constituent of aluminous ash and result of $\mathrm{X}$-ray analysis

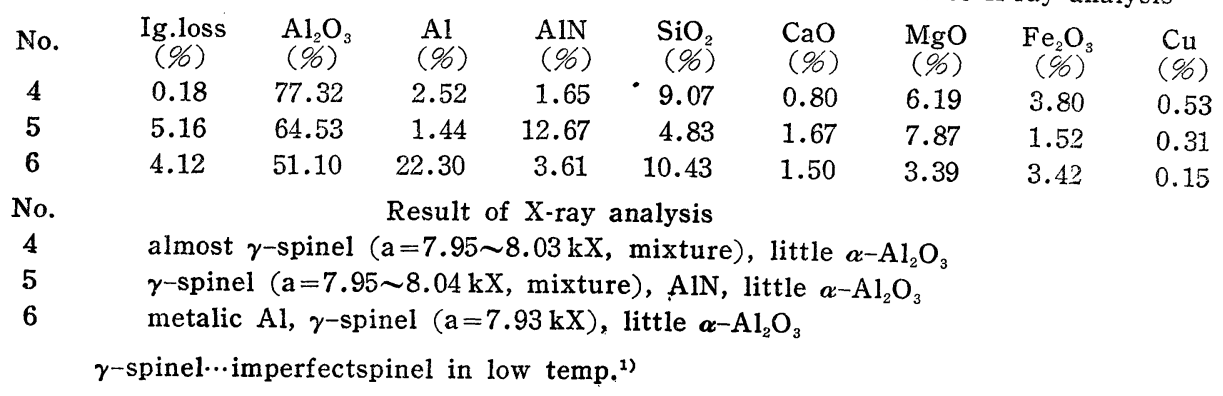

この残灰を $1300^{\circ} \mathrm{C}$ K 1 時間焼成してX線分析した 結果は窒化アルミニウム, 金属アルミニウムの廻折線 は消滅し，いずれる スピネルは試料 4 と 6 では完全スピネル $\left(\mathrm{MgO} \cdot \mathrm{Al}_{2} \mathrm{O}_{3}\right.$ $\mathrm{a}=8.06 \mathrm{kX})$ が認められ, 試料 5 では $\gamma$-スピネル $(\mathrm{a}=8.00 \sim 8.04 \mathrm{kX})$ が認められた。また試料 4 と6 ではムライトが少量諗められた。

試料 6 特侍金属アルミニウムが多く自然性であ り，常温で点火して子発火しないが，約 $200^{\circ} \mathrm{C}$ 亿加 熱してその一部酸化削を作用させて点火すると燃焼 が次第全体に伝播し，熱源なしで約 $1200^{\circ} \mathrm{C}$ 程度の 烧成を行らことができる。然焼物をX線分析した結 果, $\boldsymbol{a}$ ーアルミナと り少量のムライトを認めるが窒化アルミニウムははを んぞ認められない。この方法がアルミナ烧成物を゙得る
ための最す安価な方法と考兄られる。

このような焼成アルミ残灰をポットミルで 10 時間 粉砕後, 適量の硬化脂肪酸と加温湜和して油脂研磨材 を製造した。この製品の製造条件と試験結果を第 10 表に示す。

これらの結果でわかるようと, アルミ残灰は未焼成 または $1000^{\circ} \mathrm{C}$ 以下の焼成でる軟質金属注しては, ある程度の研磨力をすっててい。 $1000^{\circ} \mathrm{C}$ 以上の焼成 では硬質金属対しても研既力をるつよ5になる。試 料6.燃烊物も同様の性能がある。これらのととはX 線分析結果ともよく一致している。乙か乙燒結性であ るため仕上力は十分でなく，精仕上用としては適当と はい光ないが，鋉仕上用または下地研硢用としては土 分である。 
Table 10 Properties of fatty abrasive from aluminous ash

\begin{tabular}{|c|c|c|c|c|c|c|c|c|}
\hline \multirow{2}{*}{$\begin{array}{l}\text { Aluminous } \\
\text { ash No. }\end{array}$} & \multicolumn{2}{|c|}{ Calcining Condition } & \multirow{2}{*}{$\begin{array}{c}\text { Fatty acid } \\
(\%)\end{array}$} & \multicolumn{5}{|c|}{ Abrasive and finishing power } \\
\hline & $\left({ }^{\circ} \mathrm{C}\right)$ & (h) & & $\mathrm{Ni}$ & St & $\mathrm{Cu}$ & Brs & Al \\
\hline 4 (raw) & - & - & 20 & $5 \mathrm{C}$ & $5 \mathrm{C}$ & $>10 \mathrm{C}$ & $>10 \mathrm{C}$ & $>10 \mathrm{C}$ \\
\hline 4 & 600 & 2 & 20 & $5 \mathrm{C}$ & $0.5 \mathrm{~B}$ & $5 \mathrm{C}$ & $5 \mathrm{~B}$ & $5 \mathrm{C}$ \\
\hline 4 & 800 & 1.5 & 20 & $7 \mathrm{C}$ & $8 \mathrm{C}$ & $>10 \mathrm{C}$ & $>10 \mathrm{C}$ & $>10 \mathrm{C}$ \\
\hline 4 & 1000 & 1 & 20 & $7 \mathrm{C}$ & $8 \mathrm{C}$ & $>10 \mathrm{C}$ & $>10 \mathrm{C}$ & $>10 \mathrm{C}$ \\
\hline 4 & 1200 & 1 & 20 & $9 \mathrm{C}$ & $8 \mathrm{C}$ & $>10 \mathrm{C}$ & $>10 \mathrm{C}$ & $>10 \mathrm{C}$ \\
\hline 5 (raw) & - & - & 20 & $2.5 \mathrm{~B}$ & $3 \mathrm{C}$ & $5 \mathrm{~B}$ & $10 \mathrm{C}$ & $10 \mathrm{C}$ \\
\hline 5 & 800 & 2 & 20 & $10 \mathrm{C}$ & $5 \mathrm{C}$ & $10 \mathrm{C}$ & $10 \mathrm{C}$ & $>10 \mathrm{C}$ \\
\hline 5 & 1000 & 1 & 20 & $10 \mathrm{C}$ & $5 \mathrm{~B}$ & $10 \mathrm{C}$ & $10 \mathrm{C}$ & $>10 \mathrm{C}$ \\
\hline 5 & 1200 & 1 & 20 & $10 \mathrm{C}$ & $5 \mathrm{~B}$ & $>10 \mathrm{C}$ & $>10 \mathrm{C}$ & $>10 \mathrm{C}$ \\
\hline 6 & self combustion & - & 20 & $10 \mathrm{C}$ & $5 \mathrm{C}$ & $>10 \mathrm{C}$ & $>10 \mathrm{C}$ & $>10 \mathrm{C}$ \\
\hline
\end{tabular}

結論

（1）精仕上用としてはパイヤー法によるアルミナ 単味を $1100 \sim 1250^{\circ} \mathrm{C}$ 飞焼成して微粉砕したものを原 料とした油脂研碳材が良好で，アルカリを添加焼成し たものは研磨力が劣り, 滑石を添加烓成したものは仕

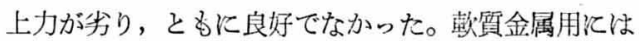
比䩙的低温燒成のるのぶよく，硬質金属用飞嵪高温焼 成のものが良好であった。酸化クロムを原料とする青 棒に比較すると硬質金属に対してやや劣る点がある が，軟質金属に対しては優少なく，俩格の安い点を考

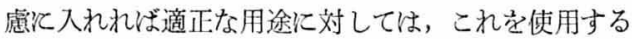
ことが有利と考えられる。

（2）焼成ボーキサイトをたは燃成アルミ残灰を使 用した油脂研磨材は研臂力で純アルミナに匹敵する
るのが得られるが, 㤸結珄であるため仕上力が分る。 しかし，粗仕上用または下地斫㗔用としてはトリポリ 以上の性能があり，価格もこれそ対抗し得るので極め て有望である。

（3）アルミ残灰に金属アルミニウムを相当残存さ

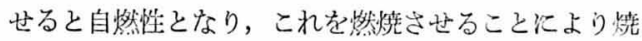
成効果を岕れ゙れば，焼成費がなくなるので特化有望で める。

(4) ボーキサイト焼成漈して $\mathrm{Al}_{2} \mathrm{O}_{3} \cdots \mathrm{Fe}_{2} \mathrm{O}_{3}$ 系 固溶体が認められたが，とのよ5な固溶仗系研砣材は 今後の問題である。

交献

1）山口悟郎，筀協，61594 (1953)

2) 山口悟郎, 墨協, 5542 (1947)

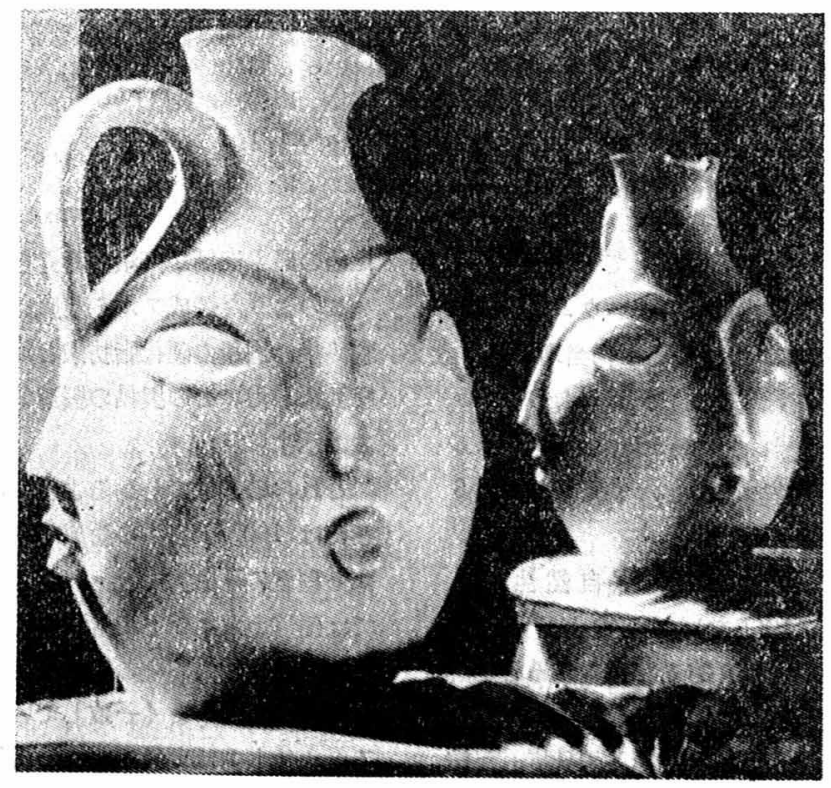

Gerhard Liebenthron 作

Keramische Zeitschrift 誌 1953 年 9 月号 475 頁より転载 